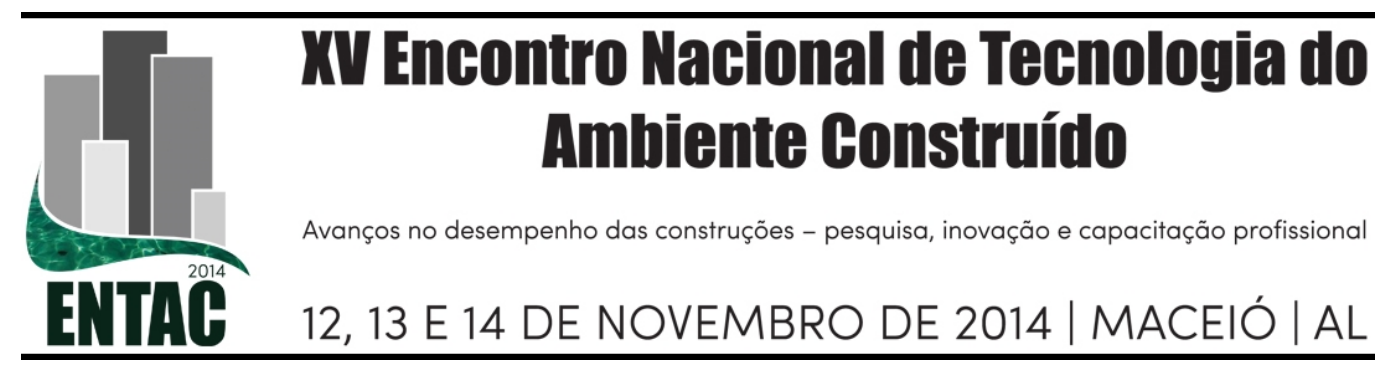

\title{
EXAUSTORES EÓLICOS COMO FONTE DE GERAÇÃO DE ENERGIA ELÉTRICA: ESTUDO DE CASO EM COZINHA INDUSTRIAL EM CUIABÁ-MT
}

\author{
MATIAS, Fátima Elizabete dos Reis (1); OLIVEIRA, Angela Santana de (2); \\ MOURA, Walterley Araújo (3); OLIVEIRA, Marco Aurélio (4)
}

(1) Eng ${ }^{a}$ Civil Msc. do Instituto Federal de Ciência e tecnologia de Mato Grosso (IFMT). E-mail : fatima.matias@ifmt.edu.br; (2) Prof $\mathrm{Dr}^{\mathrm{a}}$ do Instituto Federal de Ciência e tecnologia de Mato Grosso Campus Cuiabá (IFMT). Departamento da Área de Construção Civil (DACC). E-mail:

angela.oliveira@cba.ifmt.edu.br; (3) Prof. Dr. do Instituto Federal de Ciência e tecnologia de Mato Grosso - Campus Cuiabá (IFMT). Departamento da Área de Eletro-eletrônica (DAEE). E-mail: walterley.moura@cba.ifmt.edu.br; (4) Prof. Dr. da Universidade de Brasília (UNB). Departamento Engenharia Elétrica (ENE). E-mail: mago@ene.unb.br

\begin{abstract}
RESUMO
Com a finalidade de minimizar os impactos ambientais causados pelo setor da construção civil, as instituições ligadas a este setor organizaram-se e implantaram práticas sustentáveis, buscando produtos associados à sustentabilidade. Está pesquisa objetivou demonstrar propostas para o desenvolvimento de protótipos capazes de gerar energia elétrica com a utilização de exaustor eólico interligado a uma lâmpada de emergência sem a interferência da rede elétrica. $O$ ambiente de estudo escolhido foi a cozinha industrial do Instituto Federal de Educação, Ciência e Tecnologia de Mato Grosso (IFMT), em razão de se constatar alto grau de calor neste ambiente, principalmente, em horários de pico de cocção. O resultado do experimento contribuiu para a análise de comparações de novos métodos para se utilizar a energia eólica, em pequenas gerações de energia elétrica. Para isso, foram propostos 4 processos construtivos, utilizando-se o exaustor eólico como fonte de energia elétrica. $\mathrm{O}$ melhor resultado foi o projeto desenvolvido para a construção de um gerador eólico com bobinas e imãs permanentes, de baixa potência, a ser acionado pelo vento. Este projeto, denominado "Processo com bobina e neodímio", tem caráter inovador em vários sentidos, além de ser um provável produto a ser produzido em escala comercial. É de fácil montagem, custo acessível, com um potencial superior ao analisado para pequenas gerações de energia. Foram testados 03 procedimentos neste método e o Exaustor com 190 neodímios de $10 \mathrm{mmx} 5 \mathrm{~mm}$ acendeu uma lâmpada de emergência com 36 leds. Os resultados obtidos demonstraram que é possível aproveitar o movimento dos exaustores como fonte de geração de energia elétrica. $\mathrm{O}$ trabalho resulta uma relevante contribuição para melhoria da qualidade de vida das pessoas e, sobretudo, contribui para a sustentabilidade na construção civil, apontando soluções com o uso de geração de energia elétrica produzida por exaustores eólicos, como fonte alternativa e limpa.
\end{abstract}

Palavras-chave: Energias renováveis, sustentabilidade, geração de energia.

\begin{abstract}
Finality to minimize the environmental impacts caused by the construction industry, related institutions to this sector are organized and implemented sustainable practices, seeking products associated with sustainability. Study is aimed to demonstrate proposals for developing of prototypes capable of generating electricity with the use of connected to an emergency lamp without interference of the exhaust electric grid wind energy. The study environment was chosen industrial kitchen Federal Institute of Education, Science and Technology of Mato Grosso (IFMT), because it is found high level of heat in this environment, especially during peak hours of cooking. The result of the experiment contributed to the
\end{abstract}


analysis of comparisons of new methods for using wind energy in small generations of electricity. For this, 4 construction processes have been proposed, using the wind as a source of exhaust energy. The best result was the project designed for the construction of a wind generator with permanent magnets and reels, low-power, to be powered by the wind. This project, called "Process with coil and neodymium," is innovative in many ways, besides being probable product to be produced on a commercial scale. It is easy to mount, affordable price, with a higher potential for the considered of small power generations. It was testing 03 procedure in this method and the exhaust fan with 190 neodimios of 10mmx5mm sparked an emergency lamp with 36 Leds. The results demonstrated that it is possible to enjoy the movement of the exhaust as a source of electrical power generation. The work results in a significant contribution to improving the quality of life and, above all, contributes to sustainability in construction, pointing solutions with the use of electric energy produced by wind exhaust, as an alternative and clean energy source.

Keywords: Renewable energy, sustainability, power generation

\section{INTRODUÇÃO}

A construção civil, atualmente, está sendo um dos mais relevantes setores da economia brasileira. Possui uma cadeia de empresas interligadas na produção de insumos e serviços e, desta forma, passa a ser um setor responsável por consumir energia, água e materiais responsáveis por emissão, em grande escala, de gases "efeito estufa" ( Leite). No entanto, com a implantação do Sistema de Construção Sustentável, vem intensificando intervenções no meio ambiente, sem esgotar os recursos naturais, proporcionado a conservação para as gerações futuras, mediante a utilização de técnicas inteligentes e ecomateriais, fomentando a redução da poluição, promovendo o uso eficiente da água e de energia, e oportunizando o conforto de seus usuários.

A eletricidade tornou-se a principal fonte de luz, calor e força utilizada no mundo moderno. Grande parte dos avanços tecnológicos dependem da energia elétrica, várias atividades tais como assistir à televisão e navegar na internet são possíveis porque a energia elétrica chega até às residências. As fábricas, supermercados, shopping centers e uma infinidade de outros lugares precisam dela para funcionar. A eletricidade é transportada e chega aos consumidores no mundo inteiro por meio de sistemas elétricos complexos, compostos de quatro etapas: geração, transmissão, distribuição e consumo (ELETROBRAS, 2010). O primeiro passo para produzir energia elétrica é obter a força necessária para girar as turbinas das usinas de eletricidade.

Grande parte dos recursos energéticos do país localiza-se em regiões pouco desenvolvidas, distantes dos grandes centros consumidores e com fortes restrições ambientais. Promover o desenvolvimento econômico dessas regiões, preservar a sua diversidade biológica e garantir o suprimento energético de regiões mais desenvolvidas são alguns dos desafios da sociedade brasileira. Torna-se fundamental, portanto, o conhecimento sistematizado da disponibilidade de recursos energéticos, das tecnologias, dos sistemas de aproveitamento e das necessidades energéticas setoriais e regionais do país (ANEEL, 2012).

O objetivo desta pesquisa foi avaliar a capacidade de geração de energia elétrica produzida por exaustores eólicos para utilização como fonte de energia elétrica alternativa e renovável. $\mathrm{O}$ estudo foi desenvolvido em uma cozinha industrial do IFMT - Campus Cuiabá.

O exaustor eólico, além de não consumir energia elétrica, oferece outros benefícios e vantagens, tais como: totalmente silencioso, baixo custo de instalação e manutenção, amortização imediata, não produz fagulhas e/ou centelhas, elimina riscos de incêndio, possibilita reduções na apólice de seguro contra incêndio, funciona de forma ininterrupta; reduz odores, gases tóxicos e partículas em suspensão; remove o ar quente 
no verão e a umidade no inverno; aproxima a temperatura interna da externa à sombra, e adéqua a empresa às exigências da Norma NR-9 "Riscos Ambientais", do Ministério do Trabalho. Sua manutenção consiste em trocar esporadicamente os dois rolamentos que compõem sua parte móvel. Nos Exaustores Eólicos os rolamentos duram, em média, 05 anos, em Exaustores Eólicos 100\% em alumínio (à prova de corrosão) foi constatada vida útil de 06 anos.

Quanto aos exaustores eólicos também é sugerida a instalação em ambientes que apresentem as seguintes características: não possuem forros, com máquinas que produzem calor, quando acionadas, com fluxo relativo de pessoas, em locais de criação de animais, pois, os animais são os que mais sofrem com o calor, principalmente estando em confinamento, onde o calor pode ocasionar até mesmo mortandade. $\mathrm{O}$ Exaustor Eólico, nestes casos, ameniza a temperatura e renova o ar, tornando-o mais

fresco e saudável. O Exaustor Eólico retira os vapores evitando a condensação. É indicado, principalmente, para locais para armazenagem, que abrigam produtos que acumulam umidade.

\section{MATERIAIS E METODOS}

A area de estudo pesquisa foi desenvolvida em Cuiabá-MT, seu clima é do tipo Aw de Koppen, classificado como Tropical semi-úmido, com temperaturas que oscilam entre $30^{\circ} \mathrm{C}$ e $36^{\circ} \mathrm{C}$, apresentando duas estações bem definidas, uma seca (outono-inverno) com quatro a cinco meses secos e uma chuvosa (primavera-verão).

Foi escolhida a cozinha industrial do IFMT Campus Cuiabá como local de investigação. A cozinha possui uma área de $70 \mathrm{~m}^{2}$, contém vários equipamentos elétricos, fornos industriais, fogão industrial e uma coifa de 2,30x1,2m. O setor de administração da cozinha conta com o apoio de dois funcionários, e o processo industrial é realizado por cinco funcionários que se revezam em dois turnos, manhã (almoço) e tarde (jantar). No local existem vários equipamentos elétricos, os quais consomem $2204 \mathrm{KWh}$, mensalmente.

O desenvolvimento deste trabalho baseou-se na pesquisa de Matias(2013), inicialmente, na proposta de estudar e desenvolver um protótipo capaz de gerar e fornecer energia utilizando o exaustor eólico. Este equipamento é acionado pela força do vento com o propósito de renovar o ar do ambiente onde estiver instalado. $\mathrm{Na}$ ausência de vento, o equipamento funcionará apenas pelo diferencial térmico natural, analisando a viabilidade da integração de um conjunto de exaustores eólicos para geração de energia elétrica, com lâmpadas de emergência, sem ligação à rede elétrica, "off grid", em uma cozinha industrial.

Esta pesquisa foi estruturada de forma a estabelecer uma análise descritiva da metodologia utilizada para o desenvolvimento da pesquisa, utilizando o exaustor eólico como fonte geradora de energia, apresenta a revisão bibliográfica, contextualizando a importância das construções sustentáveis no mundo e a utilização das energias renováveis. Realizar uma abordagem do estudo de caso, discorre sobre os métodos e materiais utilizados na cozinha industrial para a coleta de dados, resultando na confecção do protótipo de exaustor eólico para geração de energia alternativa, e apresentar os resultados do experimento, com comparações de procedimento e seus respectivos resultados e vantagens e desvantagens, concluindo com sugestões para estudos posteriores. 
Atualmente, a cozinha possui uma pequena área de cocção (cozimento) e conta com um exaustor elétrico para sugar o calor gerado no ambiente, através de uma coifa fixada em cima do fogão industrial.

O propósito foi de produzir um protótipo, capaz de realizar sua finalidade, agregando, ao mesmo tempo, a produção de energia elétrica, obtida por uma fonte renovável. Para tanto, foi utilizada uma metodologia para analisar o potencial energético desperdiçado do exaustor eólico, coletado os dados da temperatura gerada na cozinha industrial, mediante instalação de sensores, verificando os pontos críticos do ambiente, fazendo o cálculo da massa calórica, e testando 4 processos para se definir o protótipo a ser utilizado no local.

\subsection{Materiais e Equipamentos}

Os materiais e equipamentos utilizados foram:

a) Sensor de temperatura - data loggers portáteis, marca novus, registrador eletrônico de temperatura, que foi utilizado na coleta de dados das temperaturas no ambiente da cozinha industrial.

b) Anemômetro - É um medidor de velocidade do vento, digital portátil da Instrustherm , e pode medir o vento em $\mathrm{m} / \mathrm{s}, \mathrm{km} / \mathrm{h}$, nós, mph e $\mathrm{ft} / \mathrm{min} / \mathrm{TBM}$ - Medidor de temperatura, umidade relativa do ar, que foi utilizado para verificar a velocidade do vento aplicada nos processos.

c) Tacômetro - Foi utilizado este equipamento, digital marca Minipa, para medir a velocidade de rotação em RPM da máquina, aplicada em cada processo.

d) Multímetro digital - Este aparelho, marca instrutherm foi destinado para medir e avaliar grandezas elétricas aplicada nos processos.

e) Fonte de corrente contínua - A fonte de corrente, marcaMinipa, pode chegar 20V / 10 A, foi utilizada na aplicação de corrente para verificar a potência do gerador.

f) Exaustor elétrico - Industrializado em Cuiabá pela empresa Renovar Instruía e Comercio. Este equipamento foi instalado no tubo da coifa, com objetivo da retirada de ar poluído ou simplesmente para ventilação do ambiente como indústrias.

g) Coifa - Utilizada na cozinha industrial do IFMT Campus de Cuiabá, possui um tubo e um chapéu, que ficam sob o telhado

\subsection{Metodologias para Coleta de Dados}

A coleta de dados iniciou-se com a medição de temperatura no ambiente da cozinha industrial, para verificar a real situação do local quanto ao fator térmico. Após, foi realizado um levantamento dos pontos críticos do local e calculou-se a quantidade de calor produzido no tubo da coifa.

No laboratório de energias renováveis do IFMT Campus Cuiabá, foram realizadas as análises do potencial de geração de energia elétrica dos 4 protótipos, utilizando o exaustor eólico.

\subsubsection{Testes no laboratório dos protótipos para geração de energia elétrica}

Para os testes no laboratório, foi utilizado um exaustor eólico, onde os mesmos retiram as massas de ar quente acumuladas nas áreas mais altas dos galpões, em todos os ramos de atividade, renovando o ar interno e facilitando a entrada de ar pelas portas e janelas dos ambientes,

Os testes de laboratório dos 4 processos, com o objetivo principal de gerar energia elétrica utilizando um exaustor eólico, foram desenvolvidos, conforme se descreve: 


\section{a) Processo com o dínamo}

O dínamo de bicicleta é um gerador de eletricidade, que acoplado à borda do exaustor Figura 01- Dínamo de bicicleta de $12 \mathrm{~V}$ eólico, transforma energia mecânica em energia elétrica, onde a variação do campo magnético gera corrente elétrica. Esta corrente elétrica acende uma lâmpada led. No projeto foi utilizado o dínamo de $12 \mathrm{v}$, para alimentar 3 lâmpadas Leds, de 1,5 V cada, (figura 01).

\section{b) Processo com bobina e neodímio}

Este processo utilizou Bobinas e Neodímios, tipo Relight ${ }^{1}$ (kit SL 520)- tecnologia "state-of-the-art"2: Através da indução eletromagnética, ou seja, com imãs "neodynium", que passam pela bobina, gerando, assim, uma corrente elétrica que alimenta as luzes de uma maneira ecologicamente correta. Foram utilizados: Exaustor Eólico; Luminária de 36 leds; Bobina de 12 volts; 195 Neodímios de $10 \mathrm{~mm}$ por $5 \mathrm{~mm}$; 14 Neodímios de $20 \mathrm{~mm}$ por $2 \mathrm{~mm}$.

Para esse experimento foi desenvolvido um gerador utilizando o próprio aro do exaustor eólico, como base móvel acoplando os neodímios, transformando-o em rotor, e a bobina sustentada pela base fixa do exaustor, o qual pode se chamar de estator, (Figura 02).

\section{Figura 02- Imagem do exaustor com os neodímios e a bobina}

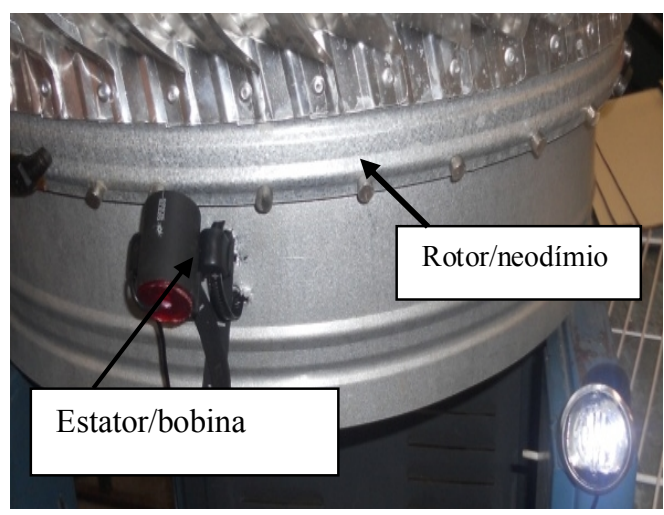

Neste processo realizaram-se três tipos de ensaios:

O $1^{\circ}$ ensaio - Utilizou-se 42 neodímios distribuídos em torno do exaustor, com espaçamento, em média, de $5 \mathrm{~cm}$, e a bobina, de 12 volts.

O $2^{\circ}$ ensaio - Utilizou-se 42 neodímios, de $10 \mathrm{~mm} \times 5 \mathrm{~mm}$ e 14 neodímios, de $20 \mathrm{~mm} \times 2 \mathrm{~mm}$ distribuídos em torno do exaustor, com espaçamento de, em média, $3 \mathrm{~cm}$, e a bobina de 12 volts.

O $3^{\circ}$ ensaio - Utilizou-se 190 neodímios $10 \mathrm{~mm} \times 5 \mathrm{~mm}$ distribuídos em torno do exaustor, formando um cinturão, e a bobina de 12 volts.

\footnotetext{
${ }^{1}$ Relight- reacender uma luz.

${ }^{2}$ State-of-the-art - Tecnologia mais moderna.

${ }^{3}$ Neodynium - O neodímio é um material para criar um campo magnético forte para maior sensibilidade numa bobina.
} 
c) Processo com polia

Este processo utiliza o motor com correia acoplada em uma polia. O protótipo foi desenvolvido no laboratório do SENAI /PR, na cidade de Apucarana, Paraná, pelo professor Ernesto Sountachi, juntamente com a aluna Josiane Caniatu do SESI Projeto Inova, 2011. Uma função primordial deste processo utiliza o motor com correia acoplada em uma polia. Uma função primordial do exaustor é o de eliminar a má circulação do ar dentro de um ambiente. Os alunos do Colégio SESI e do SENAI, sob a orientação do professor Ernesto, aprimoraram o exaustor, equipando-o com um eixo principal, ligado a uma polia, o qual foi interligado através de uma correia ao motor de corrente contínua. No momento em que o exaustor eólico gira, o mecanismo movimenta e gera energia elétrica para o motor, como demonstrado nas Figuras 3(a) e3(b).
Figura 3 -Visão da parte superior do protótipo (a); Visão da parte inferior do protótipo (a)
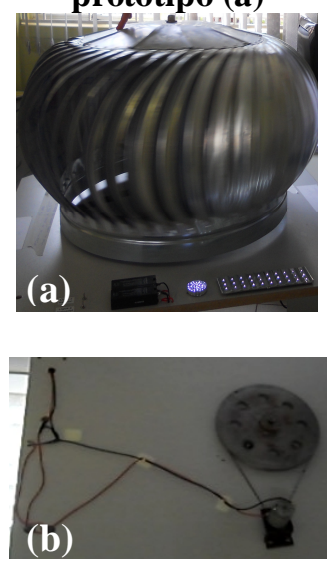

\section{d) Processo do motor acoplado ao eixo}

Para esse processo, utilizando o motor no eixo do exaustor, foi necessário adaptar o eixo do exaustor para que ele gire junto ao movimento das palhetas a fim de identificar um motor capaz de gerar energia com a rotação baixa ( Figura 4).

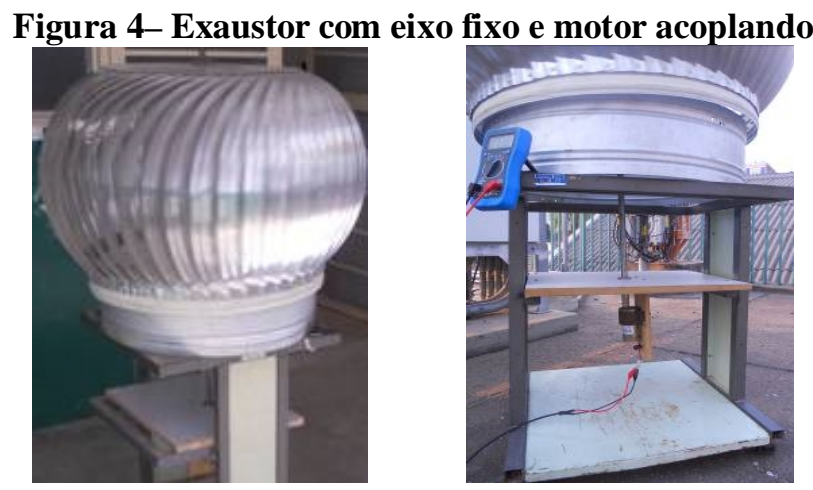

\section{RESULTADOS E DISCUSSÕES}

\subsection{Testes com dínamo de bicicleta}

No primeiro processo foi utilizado um pequeno gerador, dínamo de bicicleta, o qual é fácil de se adquirir e instalar, com custo baixo, mas a desvantagem é a de provocar um atrito na borda do exaustor eólico diminuindo a rotação natural do exaustor. No entanto, dependendo do fim desejado, poderá gerar energia. Para isso, é necessário instalar uma placa fotovoltaica, acoplada em um motor para puncionar o exaustor a girar em momentos com pouca ventilação. Desta forma, o pequeno gerador poderá contribuir com geração de energia e armazená-la, em um conjunto de baterias, para ser utilizada em luminárias de emergência.

Esta adaptação não foi bem sucedida devido ao dínamo exigir um esforço no primeiro impulso para iniciar a girar o exaustor, o qual necessita de uma rajada de vento acima de $6 \mathrm{~m} / \mathrm{s}$, e mesmo acontecendo esse impulso, o dínamo provoca atrito na borda do exaustor, dificultando o giro, e com pouca velocidade o exaustor gira muito lento de 
forma natural. Para atingir o objetivo almejado, necessita de outros impulsos como, por exemplo, de uma placa solar acoplada em um motor para ajudar a girar com maior velocidade

\subsection{Teste com gerador com Bobinas e Neodímios - (Relight)}

No segundo processo, em um estudo preliminar, concluiu-se que o sistema de bobinas e imãs é o mais viável tecnicamente e economicamente, com pequena bobina com um cinturão de imãs, utilizando o método semelhante ao de turbinas eólicas de eixo vertical (VAWT), de pequenas dimensões e baixo custo. Este processo de construção alcançou o objetivo do protótipo: ser flexível, custo acessível, fácil montagem, baixa manutenção, fácil transporte. Para implantar em escala industrial, há necessidade de aprimoramento no desenvolvimento do produto.

Com esse processo foram realizados 3 ensaios, sendo que o $1^{\circ}$ obteve o resultado com média de 3,5 Volts de corrente alternada, com picos com mais e menos corrente, devido ao espaçamento dos neodímios distribuídos em torno da borda do exaustor. $\mathrm{O} 2^{\circ}$ ensaio foi realizado utilizando-se 42 neodímios de $10 \mathrm{~mm} \times 5 \mathrm{~mm}$ e 14 neodímios de $20 \mathrm{~mm} \times 2 \mathrm{~mm}$, instalados sempre em uma sequência de polaridade, um norte, outro sul, e assim, sucessivamente, com espaçamento entre eles, em média de $3 \mathrm{~cm}$, e a bobina de 12 volts. $\mathrm{O} 3^{\mathrm{o}}$ ensaio foi realizado juntando todos os neodímios, demonstrado (Figura $5)$.

Figura 5 - $3^{\circ}$ ensaio utilizando 190 neodímios.

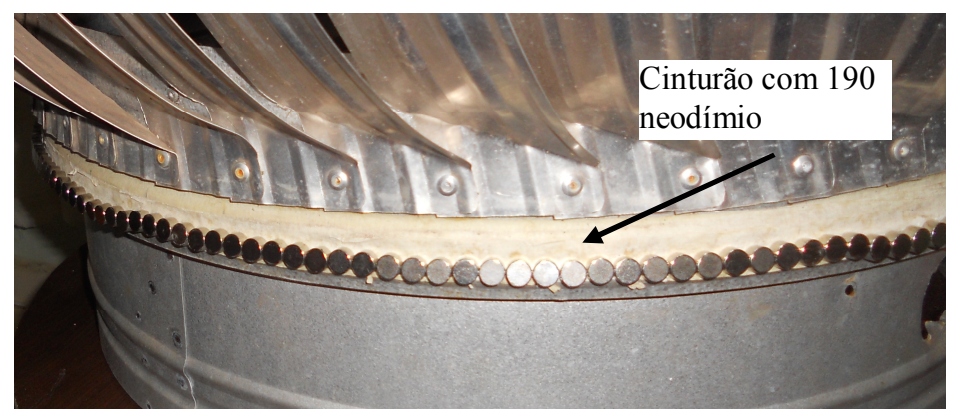

Com este ensaio foram percebidos os picos máximos da capacidade da bobina, exatamente no momento em que o cinturão de neodímios passa pela bobina, e os leds ficam com a intensidade forte e não se percebe, a olho nu, eles piscarem.

Foi realizada uma comparação, entre a rotação do exaustor e a velocidade do vento com a corrente gerada, conforme demonstrado na Tabela 1:

Tabela 1 - Comparação rotação, velocidade e corrente.

\begin{tabular}{|c|c|c|c|c|}
\hline $\begin{array}{l}\text { Ensai } \\
\text { o }\end{array}$ & Rotação & $\begin{array}{l}\text { Velocidade } \\
\text { Vento em } \mathrm{m} / \mathrm{s}\end{array}$ & $\begin{array}{l}\text { Corrente } \\
\text { media - Voltts }\end{array}$ & Observações \\
\hline 1 & 53,0 & 3,60 & 3,10 & $\begin{array}{l}\text { Os leds ficam piscando com intensidade } \\
\text { fraca. }\end{array}$ \\
\hline 2 & 67,5 & 4,70 & 5,80 & Os leds ficam mais forte. \\
\hline 3 & 77,5 & 5,80 & 6,50 & $\begin{array}{l}\text { Os leds ficam bem fortes, mas percebe-se } \\
\text { pouco o pisca dos leds. }\end{array}$ \\
\hline
\end{tabular}

\subsection{Testes com polia acoplada ao eixo}

O terceiro processo, com a polia acoplada, possui um custo baixo, fácil produção, mas, a manutenção é mais complexa. A polia deverá ser fabricada com o diâmetro de acordo com o rotação desejada, deve-se utilizar material leve, mas é de fácil montagem. $\mathrm{O}$ método utilizado gerou a energia desejada para acender 72 leds em período continuo. 
Este processo poderá ser também aproveitado, ao se inverter a instalação da polia para o topo do exaustor eólico, liberando espaço interno para o fluxo de ar, melhorando a exaustão. No entanto, tanto a polia como o gerador e a correia ficarão expostos ao tempo.

Pesquisa realizada no SENAI/SESI PR (2011), o resultado em laboratório foi satisfatório, conseguindo gerar energia para acender uma luminária de emergência com 36 leds e uma luminária com 36 leds.

Este projeto poderá ser adaptado e utilizado nos exaustores de um dos galpões, acoplado em um conjunto de baterias. A polia acoplada ao eixo na parte de baixo do exaustor, da mesma forma como foram realizados os testes, ou parte superior externa com um adaptador para o motor. Esse método gera energia por 24 horas, lançando-a a um banco de baterias, onde será armazenada e poderá fornecer energia elétrica para ser consumida em momentos críticos, utilizando para as lâmpadas de emergência ou painéis de propagandas

\subsection{Testes processo com motor acoplado ao eixo}

O quarto processo, com o motor acoplado ao eixo principal, identificou-se a possibilidade de geração de energia. No entanto, o motor fica exposto ao calor, fumaça e gordura e o motor utilizado na pesquisa necessita de uma rotação maior do que as demais propostas. Para este objetivo e necessário pesquisar outros geradores que possam funcionar com baixa rotação.

Este Processo foi aplicado para várias voltagens para avaliar a rotação necessária para gerar a energia adequada, conforme demonstra a Tabela 2.

Tabela 2 - Aplicação da voltagem com rotação do exaustor.

\begin{tabular}{|c|c|c|c|}
\hline \multicolumn{4}{|c|}{ Teste com o motor } \\
\hline $\begin{array}{c}\text { Voltagem aplicada } \\
(\mathbf{V})\end{array}$ & $\begin{array}{c}\text { Rotação } \\
(\mathbf{r p m})\end{array}$ & $\begin{array}{c}\text { Potencia } \\
(\mathbf{w})\end{array}$ & $\begin{array}{c}\text { Voltagem Gerada } \\
(\mathbf{V})\end{array}$ \\
\hline 2,2 & 158,2 & 0,5 & 6,5 \\
\hline 1,9 & 148,4 & 0,4 & 6,1 \\
\hline 1,8 & 132,2 & 0,4 & 5,5 \\
\hline 1,7 & 122,9 & 0,4 & 5,0 \\
\hline 1,6 & 109,2 & 0,4 & 4,5 \\
\hline 1,5 & 103,0 & 0,4 & 4,3 \\
\hline 1,4 & 98,6 & 0,4 & 4,0 \\
\hline 1,3 & 84,5 & 0,4 & 3,5 \\
\hline 1,2 & 71,5 & 0,4 & 3,0 \\
\hline 1,1 & 69,9 & 0,4 & 2,5 \\
\hline
\end{tabular}

\section{CONSIDERAÇOES FINAIS}

Os resultados comprovaram que o exaustor eólico pode ser utilizado como uma possibilidade de geração de energia elétrica.

No estudo em laboratório, utilizou-se o exaustor eólico com 4 diferentes tipos de protótipos com para geração de energia capazes de gerar energia alternativa, necessitando apenas definir o fim desejado e as adequações necessárias para cada processo. 
O processo onde foi empregado no gerador a bobina e um cinturão de neodímio foi o que produziu a maior quantidade energia entre os experimentos. Observou-se que o giro do exaustor é capaz de produzir energia elétrica suficiente para manter 1 lâmpada de emergência de 36 leds acessa.

Como o estudo foi desenvolvido em uma cozinha Industrial, recomendou-se que seja realizada adaptação deste processo no exaustor do ambiente, aproveitando esta fonte de energia para manter uma lâmpada de segurança.

Como o movimento do exaustor não é continuo, sugere-se em outras pesquisas a utilização de sensores e conversores de corrente alternada para continua, assim permitindo o armazenamento da energia gerado em baterias. Esta implementação tornará o sistema mais completo oferecendo a possibilidade de alimentar mais de uma lâmpada.

\section{REFERÊNCIAS}

LEITE, F.V. Certificação ambiental na construção civil. 2011.Monografia - Escola de Engenharia, Universidade Federal de Minas Gerais, Belo Horizonte.

ELETROBRÁS. Importância da energia elétrica. Rio de Janeiro, 2012. Disponível em $<$ http://www.eletrobras.com>. Acesso em: 30 de jul. 2012.

AGENCIA NACIONAL DE ENERGIGIA ELETRICA. Energia, espaço geográfico desenvolvimento. Brasília, 2012. Disponível em: $<$ http://aneel.gov.br $>$ Acesso em: 25 de jul. 2012.

MARTINS, R. Sistemas de Exaustão e Ventilação Industrial. 2007 - Serviços Brasileiro de Respostas Técnicas, Rede Tecnológica do Rio de Janeiro.

MATIAS, F.E.R. Utilização de Exaustor Eólicos como Fonte Geradora de Energia Elétrica. 2013. Dissertação de Mestrado Publicado PPGENE - Departamento de Engenharia Elétrica, Universidade de Brasília, Brasília.

BRASIL. Ministério do Trabalho e Emprego. Normas Regulamentadoras de Segurança e Saúde no trabalho, NR 9 - Programa de prevenção de riscos ambientais. Portaria SSST n. ${ }^{\circ} 25$, de 29 de dez. de 1994. Brasília. 